\title{
PENGEMBANGAN COLLABORATIVE PROBLEM SOLVING INVENTORY (CPSI) BERBASIS WEB UNTUK MENGUKUR KETERAMPILAN KOLABORASI DALAM PEMECAHAN MASALAH SISWA
}

Ika Sukmawati ${ }^{*}$, Karunia Galih Permadani ${ }^{1}$

${ }^{1}$ Universitas Tidar, Jl. Kapten Suparman No.39, Magelang, Jawa Tengah

* corresponding author | email : ikasukma@untidar.ac.id

Collaborative Problem Solving (CPS) adalah salah satu keterampilan penting abad ke-21. Keterampilan ini juga merupakan keterampilan yang harus ditanamkan pada siswa dalam pembelajaran. Pengukuran CPS dapat dilakukan dengan menggunakan instrumen berupa inventory. Dalam penelitian ini, dikembangkan Collaborative Problem Solving Inventory (CPSI) berbasis web dengan metode pengembangan Learning Development Cycle (LDC). CPSI yang dikembangkan oleh penyusun merupakan pengukuran terhadap Collaborative Problem Solving yang inovatif, menekankan pada pengukuran sebelum, selama dan sesudah kegiatan pembelajaran Collaborative Problem Solving dilakukan. Tahapan penelitian ini meliputi: (1) Observasi, Survei dan Analisis Kebutuhan; (2) Focus Group Discussion; (3) Penyusunan Desain CPSI; (4) Pengembangan CPSI Berbasis Web melalui Model Pengembangan LDC; (5) Validasi CPSI oleh ahli pengembang bahan ajar (kelayakan) dan guru (kepraktisan); dan (6) Analisis Data. Berdasarkan hasil penelitian didapatkan instrumen CPSI berbasis web dengan indikator penilaian keterampilan kolaborasi yang telah divalidasi oleh ahli dan praktisi. Hasil validasi menunjukkan bahwa instrumen layak digunakan dengan perbaikan kecil (validitas 3,75 oleh ahli media; validitas 3,78 oleh ahli evaluasi; dan rerata 3,65 oleh praktisi). Tindak lanjut penelitian dapat dilakukan dengan mengujicobakan instrumen dalam situasi pembelajaran di kelas, dengan terlebih dahulu melakukan perbaikan terkait kemenarikan tampilan dan desain website.

\section{Kata Kunci : berpikir kreatif; pembelajaran infuse; keterampilan berwirausaha}

Collaborative Problem Solving (CPS) is one of the essential skills of the $21^{\text {st }}$ century. This skill is also must be instilled in students in learning process. CPS can be gauged by using an instrument in the form of inventory. In this study, a webbased Collaborative Problem Solving Inventory (CPSI) was developed with the Learning Development Cycle (LDC) development method. The CPSI developed by the authors is a measurement of innovative Collaborative Problem Solving, emphasizing on measurements before, during and after Collaborative Problem Solving learning activities are carried out. The stages of this research include: (1) Observation, Survey and Needs Analysis; (2) Focus Group Discussion; (3) Preparation of CPSI Design; (4) Development of Web-Based CPSI through LDC Development Model; (5) CPSI validation by experts in developing teaching materials (feasibility) and teachers (practical); and (6) Data Analysis. Based on the results of the study, it was obtained that the CPSI instrument was web-based with indicators for assessing collaboration skills that had been validated by experts and practitioners. The validation results showed that the instrument is feasible to use with minor improvements (validity 3.75 by media experts; validity 3.78 by evaluation experts; and mean 3.65 by practitioners). Follow-up research can be done by testing the instrument in a classroom learning situation, by first making improvements related to the attractiveness of the appearance and website design.

Keywords : collaborative problem solving, inventory, website, instrument 
Collaborative Problem Solving (CPS) adalah salah satu keterampilan yang mulai diminati di berbagai jenjang pendidikan (Griffin \& Care, 2014). CPS merupakan keterampilan penting dalam kehidupan di abad 21. Pentingnya CPS pertama kali dikemukakan oleh Hutchins (1995). Collaborative Problem Solving juga merupakan sebuah model pembelajaran yang memungkinkan siswa berpartisipasi dalam sebuah proyek pemecahan masalah yang diselesaikan secara bersama-sama dan mendengarkan salah seorang dari rekan kerjanya untuk menjelaskan hasil dari pekerjaannya tersebut.

CPS adalah keterampilan penting yang perlu dikuasai untuk hidup dalam keluarga, hidup sebagai tenaga kerja, dan masyarakat. Hal ini karena dalam berbagai bidang kehidupan saat ini, banyak perencanaan, penyelesaian masalah, dan pengambilan keputusan yang harus dilakukan secara berkelompok. Keberhasilan kelompok dapat terancam oleh anggota tidak terampil atau yang tidak kooperatif, sedangkan hal itu dapat dicegah oleh adanya anggota tim yang mampu membantu menegosiasikan konflik, menetapkan peran, mempromosikan komunikasi tim, dan membimbing tim untuk mengatasi hambatan (Salas, Cooke, \& Rosen, 2008). CPS berbeda dari pemecahan masalah individua tau indivual problem solving (IPS). CPS diduga memiliki keunggulan dibandingkan IPS karena: (1) ada pembagian kerja yang lebih efektif, (2) solusi dalam suatu pemecahan masalah merupakan gabungan informasi dari berbagai sumber pengetahuan, perspektif, dan pengalaman, serta (3) kualitas solusi ditentukan oleh setiap ide-ide anggota kelompok (Graesser, Cai, Hu, Foltz, Greiff, \& Shaffer, 2017).

Berdasarkan hasil observasi yang menunjukkan fakta empiris di lapangan, masih sedikit guru yang telah memberdayakan dan menilai keterampilan siswa dalam kerja kolaboratif problem solving. Pelaksanaan pembelajaran telah memfasilitasi siswa untuk mengembangkan keterampilan berkolaborasi, misalnya melalui penugasan kelompok, presentasi dan diskusi, serta kegiatan praktikum di laboratorium. Dalam pelaksanaan kegiatan kolaborasi siswa, guru menyadari bahwa ada proses pemecahan masalah yang dilakukan secara berkelompok. Misalnya: (1) pada saat diskusi, siswa bekerja sama untuk menjawab pertanyaan dari temannya; (2) pada saat kegiatan praktikum, siswa bekerja sama untuk menentukan hipotesis, menganalisis data, dan menulis kesimpulan. Kolaborasi siswa dalam pembelajaran sudah dinilai oleh guru dengan menggunakan lembar observasi yang mengukur aktivitas dan sikap siswa. Namun demikian, proses pemecahan masalah dalam kolaborasi (Collaborative Problem Solving) yang dilakukan siswa masih belum diukur. Guru masih belum familiar dan memerlukan bantuan dalam memetakan indikator keterampilan kolaborasi dalam pemecahan masalah. Selain itu, juga dibutuhkan instrumen khusus untuk menilai CPS yang mudah diakses dan digunakan oleh guru dan juga siswa.

Untuk mengatasi kondisi demikian diperlukan pengembangan perangkat asesmen yang efektif. Berdasarkan penelitian Care, Griffin, Scoular, Awwal, \& Zoanetti (2015); Liu, Hao, von Davier, Kyllonen, \& Zapata-Rivera (2016); serta Raes, Schellens, De Wever, \& Benoit (2016), pengukuran CPS dapat dilakukan dengan pengukuran individu, maupun pengukuran kelompok. Penilaian terhadap CPS disarankan untuk memanfaatkan media online agar bisa fokus dan berdampak pada kemampuan selfregulation, kemampuan metakognitif, dan motivasi siswa. Pengukuran kesiapan peserta didik untuk mengikuti CPS juga seharusnya menjadi bagian penting dalam pengembangan instrumen penilaian. Mempertimbangkan pentingnya kesiapan awal peserta didik tersebut maka telaah terhadap Students Readiness for CSCL (SR-CSCL) juga dilakukan sesuai dengan pendapat Xiong, So, \& Toh (2015).

Pada level internasional, CPS dipilih sebagai salah satu keterampilan siswa yang dinilai oleh Organisation for Economic Cooperation and Development (OECD) dan Program for International Student Assessment (PISA), misalnya pada survey internasional PISA pada tahun 2015. Pada survey tersebut, PISA menggunakan agen berupa komputer dalam proses penilaian. Integrasi penggunaan web untuk mengembangkan instrumen penilaian CPS sangat dimungkinkan untuk memaksimalkan validitas dan reliabilitasnya.

Salah satu bentuk instrumen yang dapat digunakan untuk menilai CPS adalah inventory atau Collaborative Problem Solving Inventory (CPSI). CPSI merupakan pengukuran terhadap Collaborative Problem Solving yang inovatif, menekankan pada pengukuran sebelum, selama dan sesudah kegiatan pembelajaran Collaborative Problem Solving dilakukan. Pengembangannya mengacu pada item 
pengukuran CSCL dan SR-CSCL dengan langkah kerja Learning Development Cycle (LDC).

Berdasarkan uraian sebelumnya, dapat disimpulkan bahwa permasalahan yang mendasari pengembangan CPSI ini adalah: (1) belum adanya asesmen yang sudah memenuhi aspek validitas untuk mengukur collaborative problem solving, (2) perlu adanya contoh asesmen yang dapat dijadikan acuan, tersedia setiap waktu, dan dapat diakses kapan saja. Asesmen daring berbasis web menjadi pilihan yang bisa mengatasi permasalahan tersebut.

\section{METODE}

Pengembangan CPSI berbasis web ini dilakukan dengan model pengembangan Learning Development Cycle (LDC). Menurut Siemens (2005), LDC terdiri dari tahapan: (1) lingkup dan obyek desain pembelajaran, (2) penciptaan alat asesmen, (3) pengalaman Pengguna, (4) meta-evaluasi untuk menentukan keefektifan dan akurasi proses desain dan asumsi, serta (5) evaluasi formatif dan sumatif. Tahap pertama dari LDC terdiri dari planning dan analysis. Tahap ke dua terdiri dari aktivitas design, development, dan delivery. Tahap ke tiga mencakup user experience atau pengalaman desainer dalam menggunakan CPSI. Tahap ke empat yaitu meta-evaluation merupakan proses evaluasi instrumen yang sudah dikembangkan. Sedangkan tahap terakhir yaitu evaluation, dilakukan untuk meninjau secara keseluruhan kualitas instrumen yang sudah dikembangkan untuk kepentingan tindak lanjut dan pengembangan selanjutnya.

Hasil pengembangan CPSI berbasis web divalidasi oleh ahli media pembelajaran dan ahli evaluasi pembelajaran, serta diuji kepraktisannya melalui pengisian respon praktisi oleh Guru Mata Pelajaran Biologi di Kota Magelang. Pengumpulan data validasi CPSI dilakukan dengan instrumen lembar validasi ahli dan angket respon praktisi. Lembar validasi ahli memuat penilaian, saran dan komentar terhadap produk yang dikembangkan. Penilaian menggunakan 4 skala, yaitu 1 (kurang baik), 2 (cukup baik), 3 (baik), dan 4 (sangat baik). Sementara itu, penilaian angket respon praktisi menggunakan 4 skala, yaitu 1 (kurang setuju), 2 (cukup setuju), 3 (setuju), dan 4 (sangat setuju). Rata-rata skor penilaian menjadi acuan untuk mengetahui kevalidan dan kepraktisa produk yang dikembangkan. Perhitungan rata-rata skor penilaian dapat dilakukan dengan rumus (1).

$$
\mathrm{X}=\frac{\Sigma x}{n}
$$

\section{Keterangan}

$X \quad=$ rata-rata skor penilaian

$\Sigma x \quad=$ jumlah skor penilaian

$n \quad=$ jumlah indikator penilaian.

Kriteria penilaian ditentukan berdasarkan kriteria dalam Tabel 1.

Tabel 1. Kriteria Penilaian Validasi dan Respon Praktisi untuk Instrumen CPSI Berbasis Web

\begin{tabular}{lll}
\hline Skor Rata-Rata Penilaian & Kriteria Penilaian Validasi & Kriteria Penilaian Angket \\
\hline $3 \leq X \leq 4$ & Valid & Sangat Baik \\
$2 \leq X<3$ & Cukup Valid & Baik \\
$1 \leq X<2$ & Kurang Valid & Cukup Baik \\
$0 \leq X<1$ & Tidak Valid & Kurang Baik \\
\hline
\end{tabular}

\section{HASIL DAN PEMBAHASAN}

Pengembangan instrumen CPSI berbasis web yang dilakukan dengan menggunakan model LDC, mengikuti tahapan-tahapan dengan hasil sebagai berikut.

\section{Planning and Analysis}

Kegiatan planning and analysis dilakukan melalui observasi serta Focus Group Discussion yang melibatkan peneliti dengan guru mata pelajaran Biologi, serta dosen program studi Pendidikan Biologi. Berdasarkan hasil diskusi, didapatkan poin-poin sebagai berikut.

- Adanya kebutuhan yang mendesak untuk mengukur CPS pada siswa, dan pada Mata Pelajaran 
Biologi, penilaian terhadap CPS sangat mungkin untuk dilakukan mengingat karakteristik dan aktivitas siswa pada mata pelajaran Biologi banyak melibatkan pemecahan masalah.

- Pengalaman menyelenggarakan pembelajaran Biologi dari Dosen Prodi Pendidikan Biologi dan Guru Biologi SMA menunjukkan belum adanya rubrik yang khusus digunakan untuk mengukur keterampilan kolaborasi siswa/mahasiswa.

- Berdasarkan fakta-fakta tersebut, instrumen CPSI perlu dikembangkan untuk mengakomodasi penilaian CPS pada siswa.

- Saran-saran yang diberikan oleh peserta FGD terkait pengembangan CPSI yaitu:

1) mencakup seluruh indikator penilaian CPS pada siswa sehingga benar-benar mencerminkan penguasaan CPS

2) dikembangkan melalui model pengembangan tertentu yang sesuai, dalam hal ini peserta FGD mendukung penggunaan model pengembangan LDC dalam pengembangan CPSI

3) mudah diakses oleh guru dan siswa; karena salah satu prinsip dalam penilaian adalah adanya transparansi sehingga diharapkan siswa juga dapat mengetahui aspek-aspek apa saja yang dinilai dan bagaimana penilaiannya

- Peserta mendukung penggunaan web dalam pengukuran CPS dengan instrumen ini, dengan saran bahwa website yang dikembangkan mudah diakses, mudah digunakan (user friendly) baik oleh siswa maupun oleh guru.

\section{Design, Development, and Delivery}

Penyusunan desain CPSI dilakukan dengan memperhatikan indikator penilaian CPS, yang diadopsi dari Matriks CPS PISA 2015 (OECD, 2013). Dalam menilai penguasaan CPS, PISA 2015 menggunakan kerangka penilaian yang mendefinisikan keterampilan CPS yang mencakup tiga kompetensi utama. Ketiga kompetensi CPS tersebut antara lain: (1) membangun dan mempertahankan pemahaman bersama; (2) mengambil tindakan yang tepat; dan (3) membangun dan mempertahankan organisasi kelompok (Graesser, Foltz, Rosen, Shaffer, Forsyth, \& Germany, 2018).

Ada 12 indikator yang dikembangkan menjadi instrumen CPSI. Setiap indikator dikembangkan menjadi satu pernyataan inventory, dan masing-masing memiliki 4 pilihan respon. Masing-masing respon memiliiki skor 1-4. Dengan demikian total maksimal skor yang diperoleh adalah 48 untuk seluruh pernyataan dalam inventory.

Sebagai aspek delivery atau penyampaian inventory kepada penggunanya, inventory tersebut diintegrasikan dalam sebuah website. Website sebagai media penilaian CPS dipilih karena mempertimbangkan peranannya dalam kemajuan teknologi saat ini. Teknologi yang saat ini berkembang memungkinkan siswa untuk dapat mendesain proses belajar dan menilai proses tersebut secara kolaboratif. Computer-supported collaborative learning (CSCL) memfasilitasi proses belajar melalui sebuah server dan memungkinkan pesertanya untuk berbagi dan membangun pengetahuan bersama-sama (Greenstein, 2012). Dengan demikian, proses penilaian (assessment) terhadap keterampilan kolaborasi juga sangat memungkinkan untuk dilakukan dengan basis computer dan web.

Penggunaan penilaian berbasis komputer untuk CPS telah dikaji oleh sejumlah penelitian, seperti penelitian Rosen \& Tager (2013) yang mengkaji asesmen berbasis komputer untuk keterampilan CPS. Berdasarkan hasil penelitian tersebut, terungkap bahwa penggunaan tes terstandar CPS berbasis komputer lebih baik dibandingkan tes biasa. Penilaian CPS berbasis komputer melibatkan tingkat pemahaman bersama yang lebih tinggi, pemantauan kemajuan, dan umpan balik. Demikian pula hasil penelitian yang dilakukan oleh Graesser et al. (2017) bahwa penggunaan komputer cocok untuk menilai CPS secara sumatif karena bersifat lebih reliable dan valid.

Lebih lanjut, Graesser et al. (2018) menambahkan bahwa penilaian CPS berbasis komputer memungkinkan guru untuk melakukan penilaian terhadap siswa dengan komposisi kelompok yang lebih beragam. Selain itu, penilaian CPS berbasis komputer mampu mengungkap banyak permasalahan terkait kolaborasi dalam waktu yang singkat. Penguasaan siswa terkait CPS kemudian dapat diukur dengan sejauh mana siswa menanggapi permintaan dan memulai tindakan atau komunikasi demi mencapai tujuan kelompok.

Website yang digunakan untuk menyampaikan CPS Inventory pada penelitian ini adalah website 
hasil pengembangan peneliti yang beralamat di https://www.cpsinventory.id/. Gambar 1 menunjukkan tampilan menu utama home pada website.

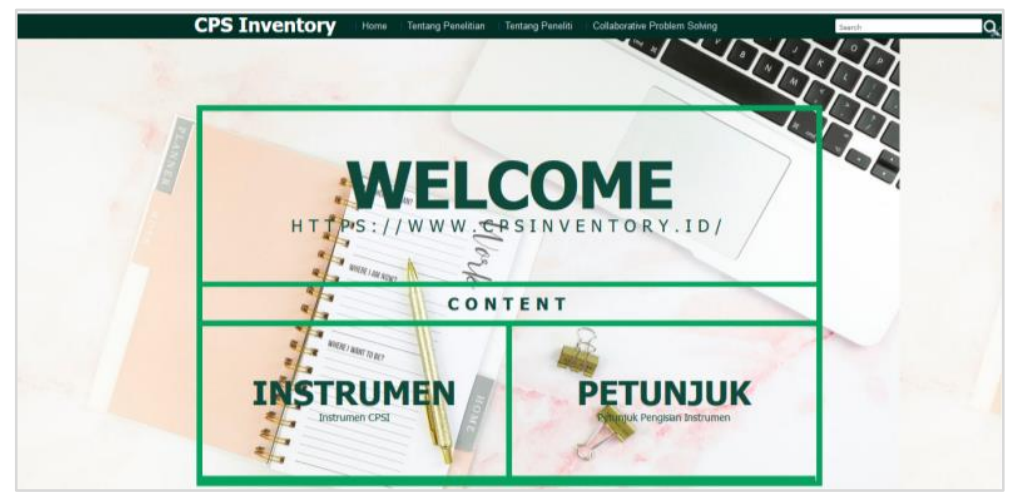

Gambar 1. Halaman Home pada Website CPSI

Berdasarkan Gambar 1, dapat dilihat bahwa terdapat menu instrumen yang berisi CPS Inventory dan Petunjuk Pengisian Instrumen. Jika pengguna memilih menu instrumen, maka pengguna akan dapat mulai melakukan pengisian inventory, dengan tampilan seperti pada Gambar 2.

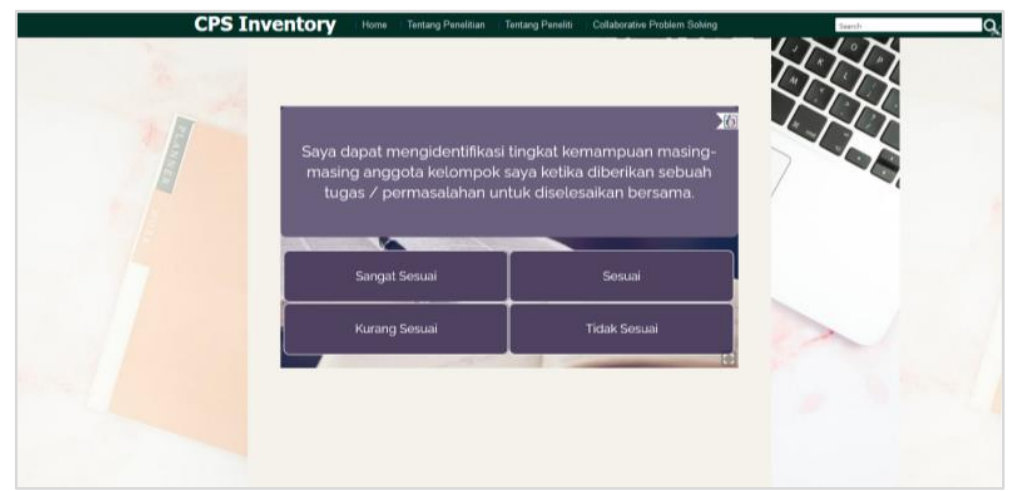

Gambar 2. Contoh Tampilan Inventory pada Website CPSI

\section{User Experience}

Berdasarkan pengalaman peneliti dalam mengembangkan CPSI berbasis web, didapatkan hasil bahwa website yang dikembangkan sudah relatif mudah diakses dan digunakan. Website cukup sederhana sehingga tidak sulit untuk dioperasikan. Selain itu, adanya petunjuk penggunaan instrumen dan informasi ringkas terkait CPS juga sudah membantu pengguna dalam mengisi inventory dalam menu Instrumen. Kekurangan yang dirasakan peneliti dalam mengembangkan website dan CPS inventory adalah dari aspek desain website dan tampilannya.

\section{Meta-Evaluation}

Meta-evaluation dalam penelitian ini dilaksanakan melalui validasi oleh ahli media dan ahli evaluasi pembelajaran, serta uji kepraktisan oleh praktisi atau guru mata pelajaran Biologi.

\section{Validasi Ahli Media}

Hasil validasi ahli media dilakukan berdasarkan aspek-aspek dan indikatornya dapat dilihat pada Tabel 2.

Berdasarkan Tabel 1, kriteria penilaian untuk rata-rata skor penilaian oleh validator ahli media adalah 3,75. Dengan demikian, CPSI berbasis web yang telah dikembangkan memenuhi kriteria valid.

Adapun saran dari validator adalah sebaiknya di sisi kanan atau kiri template ada informasi terkait kegunaan web ini, yang mencakup apa, mengapa, dan bagaimana menggunakannya. Tidak perlu menggunakan bahasa yang terlalu kaku, agar orang awam pun bisa secepatnya mengerti kegunaan website ini. Pada halaman depan saat masuk di menu instrumen, sebaiknya ada petunjuk untuk 
menggunakan dan mana yang harus di klik. Hal ini sudah dipenuhi oleh peneliti pada bagian menu Petunjuk di halaman home. Solusi yang dapat dilakukan adalah memberikan kalimat perintah pada bagian menu instrumen.

Tabel 2. Aspek dan Indikator Penilaian CPSI Berbasis Web oleh Validator Ahli Media

\begin{tabular}{|c|c|c|c|}
\hline No & Aspek & Indikator & Skor \\
\hline \multirow[t]{8}{*}{1} & Kegunaan & 1. Kemudahan untuk dioperasikan & 4 \\
\hline & (Usability) & 2. Kejelasan interaksi dengan website jelas dan kemudahan untuk dimengerti & 3 \\
\hline & & 3. Kemudahan untuk navigasi & 4 \\
\hline & & 4. Kemenarikan tampilan & 3 \\
\hline & & 5. Kesesuaian tampilan dengan jenis website & 4 \\
\hline & & 6. Adanya tambahan pengetahuan dari informasi website & 4 \\
\hline & & 7. Ketepatan penyusunan tata letak informasi & 3 \\
\hline & & 8. Kemudahan untuk menemukan alamat website & 4 \\
\hline \multirow[t]{7}{*}{2} & Kualitas & 9. Reliabilitas informasi yang disediakan oleh website & 4 \\
\hline & Informasi & 10. Kemutakhiran informasi yang disediakan oleh website & 4 \\
\hline & (Information & 11. Kemudahan informasi untuk dibaca dan dipahami & 3 \\
\hline & Quality) & 12. Ketersediaan informasi yang cukup detail & 4 \\
\hline & & 13. Relevansi informasi yang disediakan oleh website & 3 \\
\hline & & 14. Akurasi informasi yang disediakan oleh website & 4 \\
\hline & & 15. Kesesuaian informasi dengan format & 4 \\
\hline \multirow[t]{4}{*}{3} & Kualitas & 16. Mempunyai reputasi yang baik & 4 \\
\hline & Interaksi & 17. Menyediakan keamanan untuk pengunjung & 4 \\
\hline & Pelayanan & 18. Menjaga keamanan data pribadi pengunjung & 4 \\
\hline & $\begin{array}{l}\text { (Service } \\
\text { Interaction } \\
\text { Quality) }\end{array}$ & 19. Kemudahan bagi pengunjung untuk berkomunikasi dengan pengembang & 4 \\
\hline 4 & $\begin{array}{l}\text { Keseluruhan } \\
\text { (Overall } \\
\text { Impression) }\end{array}$ & 20. Tampilan situs secara keseluruhan baik. & 4 \\
\hline
\end{tabular}

$$
\text { Rata-Rata Skor Penilaian }=\frac{\text { Jumlah Skor Penilaian }}{\text { Jumlah Indikator }}=\frac{75}{20}=3,75 .
$$

\section{Validasi Ahli Evaluasi Pembelajaran}

Hasil validasi ahli evaluasi dilakukan berdasarkan aspek-aspek dan indikatornya dapat dilihat pada Tabel 3.

Berdasarkan Tabel 1, kriteria penilaian untuk rata-rata skor penilaian oleh validator ahli evaluasi pembelajaran adalah 3,78 . Dengan demikian, CPSI berbasis web yang telah dikembangkan memenuhi kriteria valid. Adapun saran dari validator adalah memberikan kontak person pada website. Untuk mengakomodasi saran ini, pengembang sudah memberikan kontak dalam bentuk email yang dapat dihubungi oleh pengguna. Selain itu, perlu digunakan pernyataan yang bersifat negatif selain pernyataan positif pada inventory.

Validator juga memberikan masukan terkait frekuensi pengisian instrumen pada website tersebut. Terkait hal ini, pengguna dapat mengisi instrumen lebih dari satu kali untuk keperluan memantau perkembangan diri sendiri. Inventory ini diintegrasikan dalam website dengan harapan agar dapat diakses oleh siswa kapanpun diperlukan. Hal ini penting sebagai upaya untuk menumbuhkan self-regulation pada siswa yang penting untuk perkembangan keterampilan berpikir tingkat tinggi, seperti keterampilan metakognitif. Sejumlah penelitian juga mendukung penggunaan website dan komputer dalam kegiatan belajar siswa, yang dapat mengembangkan kemampuan selfregulation, misalnya Steffens (2001) serta Winters, Greene, \& Costich (2008). 
Tabel 3. Aspek dan Indikator Penilaian CPSI Berbasis Web oleh Validator Ahli Evaluasi Pembelajaran

\begin{tabular}{|c|c|c|c|}
\hline No & Aspek & Indikator & Skor \\
\hline \multirow[t]{7}{*}{1} & Website & 1. Kemudahan untuk menemukan alamat website & 4 \\
\hline & CPSI & 2. Kemudahan untuk dioperasikan & 4 \\
\hline & & 3. Kemudahan untuk navigasi & 4 \\
\hline & & 4. Kesesuaian tampilan dengan jenis website & 4 \\
\hline & & 5. Adanya tambahan pengetahuan dari informasi website & 3 \\
\hline & & 6. Ketepatan penyusunan tata letak informasi & 4 \\
\hline & & $\begin{array}{l}\text { 7. Adanya kemudahan bagi pengguna untuk berkomunikasi dengan } \\
\text { pengembang website }\end{array}$ & 3 \\
\hline \multirow[t]{7}{*}{2} & $\begin{array}{l}\text { Instrumen } \\
\text { CPSI }\end{array}$ & $\begin{array}{l}\text { 8. Kesesuaian indikator yang diukur pada CPS Inventory dengan matriks } \\
\text { pengukuran Collaborative Problem Solving }\end{array}$ & 4 \\
\hline & & 9. Kesesuaian butir-butir pernyataan dalam inventory dengan indikator CPS & 4 \\
\hline & & 10. Konsistensi skala penilaian yang digunakan & 4 \\
\hline & & 11. Kesesuaian respon yang diberikan dengan pernyataan & 4 \\
\hline & & 12. Isi pokok pernyataan sesuai dengan tingkatan berpikir subyek & 3 \\
\hline & & 13. Tersedia panduan atau petunjuk penggunaan instrumen & 4 \\
\hline & & $\begin{array}{l}\text { 14. Kebermanfaatan instrumen untuk pengukuran CPS dalam kegiatan } \\
\text { pembelajaran }\end{array}$ & 4 \\
\hline \multirow[t]{2}{*}{3} & $\begin{array}{l}\text { Bahasa } \\
\text { yang }\end{array}$ & $\begin{array}{l}\text { 15. Kalimat yang digunakan dalam isi website dan inventory sesuai dengan } \\
\text { Bahasa Indonesia yang Baik dan Benar }\end{array}$ & 4 \\
\hline & digunakan & 16. Bahasa dalam isi website dan inventory sederhana dan mudah dipahami & 4 \\
\hline \multirow[t]{3}{*}{4} & Tampilan & 17. Tampilan website secara umum menarik & 4 \\
\hline & website & 18. Pemilihan jenis huruf, ukuran huruf, dan warna huruf yang sesuai & 3 \\
\hline & & Jumlah & 68 \\
\hline
\end{tabular}

Rata-Rata Skor Penilaian $=\frac{\text { Jumlah Skor Penilaian }}{\text { Jumlah } \text { Indikator }}=\frac{68}{18}=3,78$.

\section{Respon Praktisi / Guru Mata Pelajaran Biologi}

Tanggapan praktisi guru mata pelajaran Biologi didapatkan melalui instrumen yang sama dengan instrumen untuk ahli evaluasi pembelajaran. Ada enam orang guru yang berpartisipasi dalam pengisian angket, dengan hasil sebagaimana terlihat pada Tabel 4.

Berdasarkan Tabel 4, kriteria penilaian untuk rata-rata skor penilaian oleh praktisi guru mata pelajaran adalah 3,65. Dengan demikian, CPSI berbasis web yang telah dikembangkan memenuhi kriteria sangat baik. Adapun saran yang didapatkan terkait dengan tampilan dan desain. Responden mengungkapkan tampilan sebaiknya lebih cerah, menarik, disesuaikan dengan karakter pengguna (siswa SMA). Pemilihan warna penting agar pengguna tertarik untuk mempelajari informasi dalam website tersebut.

\section{Evaluation}

Berdasarkan tahapan pengembangan yang telah dilaksanakan sebelumnya, dapat diketahui bahwa CPSI berbasis web yang telah dikembangkan sudah memenuhi aspek validitas dan kepraktisan. Berdasarkan penilaian oleh validator dan juga responden yang menilai kepraktisannya, website sudah relatif mudah digunakan. Namun yang masih perlu ditindaklanjuti untuk keperluan pengembangan kualitas website ke depannya adalah dari aspek desain dan tampilannya.

Tampilan website memang merupakan salah satu aspek terpenting untuk menjamin minat siswa dalam belajar. Studi yang dilakukan oleh Al-Zedjali, Al-Harrasi, \& Al-Badi, (2014) menunjukkan bahwa kemenarikan suatu media di internet salah satu aspek yang mempengaruhi motivasi siswa dari sisi ekstrinsik. Desain dari suatu website yang digunakan sebagai lingkungan belajar juga terbukti mempengaruhi motivasi siswa dalam belajar (Wang \& Reeves, 2007). Dengan demikian, tindak lanjut yang perlu dilakukan untuk menyempurnakan website ini di masa depan adalah memperbaiki tampilannya agar semakin menarik bagi pengguna. 
Tabel 4. Aspek dan Indikator Penilaian CPSI Berbasis Web oleh Praktisi / Guru Mata Pelajaran Biologi

\begin{tabular}{|c|c|c|c|c|}
\hline No & Aspek & Indikator & $\begin{array}{l}\text { Jumlah } \\
\text { Skor }\end{array}$ & Rerata \\
\hline \multirow[t]{7}{*}{1} & Website & Kemudahan untuk menemukan alamat website & 23 & 3,83 \\
\hline & CPSI & Kemudahan untuk dioperasikan & 23 & 3,83 \\
\hline & & Kemudahan untuk navigasi & 23 & 3,83 \\
\hline & & 4. Kesesuaian tampilan dengan jenis website & 21 & 3,50 \\
\hline & & 5. Adanya tambahan pengetahuan dari informasi website & 22 & 3,67 \\
\hline & & 6. Ketepatan penyusunan tata letak informasi & 21 & 3,50 \\
\hline & & $\begin{array}{l}\text { Adanya kemudahan bagi pengguna untuk berkomunikasi } \\
\text { dengan pengembang website }\end{array}$ & 21 & 3,50 \\
\hline \multirow[t]{7}{*}{2} & $\begin{array}{l}\text { Instrumen } \\
\text { CPSI }\end{array}$ & $\begin{array}{l}\text { 8. Kesesuaian indikator yang diukur pada CPS Inventory dengan } \\
\text { matriks pengukuran Collaborative Problem Solving }\end{array}$ & 21 & 3.50 \\
\hline & & $\begin{array}{l}\text { 9. Kesesuaian butir-butir pernyataan dalam inventory dengan } \\
\text { indikator CPS }\end{array}$ & 21 & 3.50 \\
\hline & & 10. Konsistensi skala penilaian yang digunakan & 22 & 3.67 \\
\hline & & 11. Kesesuaian respon yang diberikan dengan pernyataan & 21 & 3.50 \\
\hline & & 12. Isi pokok pernyataan sesuai dengan tingkatan berpikir subyek & 21 & 3.50 \\
\hline & & 13. Tersedia panduan atau petunjuk penggunaan instrumen & 22 & 3.67 \\
\hline & & $\begin{array}{l}\text { 14. Kebermanfaatan instrumen untuk pengukuran CPS dalam } \\
\text { kegiatan pembelajaran }\end{array}$ & 22 & 3.67 \\
\hline \multirow[t]{2}{*}{3} & $\begin{array}{l}\text { Bahasa } \\
\text { yang }\end{array}$ & $\begin{array}{l}\text { 15. Kalimat yang digunakan dalam isi website dan inventory } \\
\text { sesuai dengan Bahasa Indonesia yang Baik dan Benar }\end{array}$ & 23 & 3.83 \\
\hline & digunakan & $\begin{array}{l}\text { 16. Bahasa dalam isi website dan inventory sederhana dan } \\
\text { mudah dipahami }\end{array}$ & 23 & 3.83 \\
\hline \multirow[t]{3}{*}{4} & Tampilan & 17. Tampilan website secara umum menarik & 22 & 3.67 \\
\hline & website & $\begin{array}{l}\text { 18. Pemilihan jenis huruf, ukuran huruf, dan warna huruf yang } \\
\text { sesuai }\end{array}$ & 22 & 3.67 \\
\hline & & Rerata & & 3,65 \\
\hline
\end{tabular}

\section{KESIMPULAN DAN SARAN}

\section{Kesimpulan}

Berdasarkan hasil penelitian, telah dikembangkan instrumen penilaian keterampilan kolaborasi dalam pemecahan masalah dalam bentuk CPSI berbasis web. Tahap pengembangan yang dilakukan adalah Learning Development Cycle (LDC) dengan lima tahapan. CPSI berbasis web telah dinilai kelayakannya oleh ahli media, ahli evaluasi pembelajaran, dan praktisi. Berdasarkan hasil validasi, dapat diketahui bahwa CPSI berbasis web memenuhi kriteria validitas 3,75 menurut ahli media dan 3,78 menurut ahli evaluasi pembelajaran. Dari aspek kepraktisan, responden yang meliputi guru mata pelajaran Biologi memberikan rerata respon 3,65 yang menunjukkan bahwa CPSI berbasis web memenuhi kriteria sangat baik sebagai instrumen penilaian keterampilan kolaborasi dalam pemecahan masalah siswa.

\section{Saran}

Berdasarkan pembahasan, saran yang dapat diberikan untuk pengembangan instrumen CPSI berbasis web ini adalah meningkatkan kualitas desain dan tampilan website agar lebih menarik bagi pengguna. Selain itu, uji coba instrumen dalam pembelajaran di kelas juga diperlukan untuk mengetahui efektivitas CPSI berbasis web ini dalam praktik penilaian keterampilan kolaborasi di situasi pembelajaran yang sebenarnya. Uji coba instrumen dapat dilakukan dalam rancangan kuasi eksperimen yang melibatkan beberapa kelompok siswa. 


\section{UCAPAN TERIMA KASIH}

Ucapan terima kasih disampaikan kepada Direktorat Riset dan Pengabdian Masyarakat yang telah memberikan pendanaan penelitian sehingga produk instrumen CPSI berbasis web ini dapat dikembangkan.

\section{DAFTAR RUJUKAN}

Al-Zedjali, K. H., Al-Harrasi, A. S., \& Al-Badi, A. H. (2014). Motivations for using social networking sites by college students for educational purposes. World Academy of Science, Engineering and Technology, International Journal of Social, Behavioral, Educational, Economic, Business and Industrial Engineering, 8(8), 2577-2580.

Care, E., Griffin, P., Scoular, C., Awwal, N., \& Zoanetti, N. (2015). Collaborative problem solving tasks. In Assessment and teaching of 21st century skills (pp. 85-104). Springer, Dordrecht.

Graesser, A. C., Cai, Z., Hu, X., Foltz, P. W., Greiff, S., \& Shaffer, D. W. (2017). Assessment of collaborative problem solving. Design recommendations for intelligent tutoring systems, 5.

Graesser, A. C., Foltz, P. W., Rosen, Y., Shaffer, D. W., Forsyth, C., \& Germany, M. L. (2018). Challenges of assessing collaborative problem solving. In Assessment and teaching of 21st century skills (pp. 75-91). Springer, Cham.

Greenstein, L. M. (2012). Assessing 21st century skills: A guide to evaluating mastery and authentic learning. Corwin Press.

Griffin, P., \& Care, E. (Eds.). (2014). Assessment and teaching of 21st century skills: Methods and approach. Springer.

Hutchins, E. (1995). Cognition in the Wild (No. 1995). MIT press.

Liu, L., Hao, J., von Davier, A. A., Kyllonen, P., \& Zapata-Rivera, J. D. (2016). A tough nut to crack: Measuring collaborative problem solving. In Handbook of research on technology tools for realworld skill development (pp. 344-359). IGI Global.

Raes, A., Schellens, T., De Wever, B., \& Benoit, D. F. (2016). Promoting metacognitive regulation through collaborative problem solving on the web: When scripting does not work. Computers in Human Behavior, 58, 325-342.

Rosen, Y., \& Tager, M. (2013). Computer-based assessment of collaborative problem-solving skills: Human-to-agent versus human-to-human approach. Retrieved on June, 2, 2014.

Salas, E., Cooke, N. J., \& Rosen, M. A. (2008). On teams, teamwork, and team performance: Discoveries and developments. Human factors, 50(3), 540-547.

Siemens, G. (2005). Learning Development Cycle: Bridging Learning Design and Modern Knowledge Needs.[WWW document] URL http://www. elearnspace. org.

Steffens, K. (2001). Self-regulation and computer based learning. Anuario de psicología/The UB Journal of psychology, 77-94.

Wang, S. K., \& Reeves, T. C. (2007). The effects of a web-based learning environment on student motivation in a high school earth science course. Educational Technology Research and Development, 55(2), 169-192.

Winters, F. I., Greene, J. A., \& Costich, C. M. (2008). Self-regulation of learning within computerbased learning environments: A critical analysis. Educational Psychology Review, 20(4), 429444.

Xiong, Y., So, H. J., \& Toh, Y. (2015). Assessing learners' perceived readiness for computer-supported collaborative learning (CSCL): a study on initial development and validation. Journal of Computing in Higher Education, 27(3), 215-239. 